\title{
Safety of coronary arteriography
}

\author{
M. C. Petch, Richard Sutton, and K. E. Jefferson \\ From The National Heart Hospital, Westmoreland Street, London
}

The mortality and morbidity of coronary arteriography are presented with particular reference to the relative safety of the Sones as compared with the fudkins technique. There were 6 deaths in 400 investigations (I.5\%), and all occurred with the fudkins technique. The morbidity is analysed for the last 250 investigations; cardiac infarction and serious dysrhythmias were more common with the fudkins technique whereas weak or absent pulses were more common with the Sones technique. Our present policy is therefore to prefer the Sones technique, even though we find it more difficult, and to reserve the Fudkins technique for some emergency investigations.

Selective coronary arteriography is now an established part of the investigation of patients with heart disease, and the operation of saphenous vein bypass grafting (Favaloro, 1968; Ross et al., 1972) in the treatment of coronary artery disease has led to large numbers of arteriograms being performed. The first technique to be introduced was that of Sones (Sones and Shirey, 1962) but, more recently, special preformed catheters have become available which allow the coronary ostia to be entered more easily (Wilson, Lee, and Amplatz, 1967; Judkins, 1967). The purpose of this communication is to present our experience of 400 coronary arteriograms with particular reference to the relative merits of the various techniques.

\section{Subjects and methods}

Four hundred coronary arteriograms were performed between October 1964 and April 1972. Detailed records have been kept since August 1970 with a view to such an analysis as this, and during these 19 months 250 investigations have been performed. The mortality is therefore considered for the whole series, while the morbidity is considered for the last 250 .

The diagnoses are given in Table $\mathrm{I}$. The most common indication for the investigation was the assessment of patients with coronary heart disease, and II of these patients were studied twice, and I three times before and after venous bypass grafting. Thus, there are 236 patients, 179 men and 57 women, the mean age being 5I.5 (range 4-72) years. Coronary arteriography was also performed on some patients before valve replacement and with the diagnosis of other forms of heart disease, e.g. cardiomyopathy, myocardial failure after valve replacement, noncardiac chest pain, and congenital anomalies of the coronary arteries.

Received 24 July 1972.

\section{TABLE I Diagnoses}

\begin{tabular}{lr}
\hline Coronary heart disease & I23 \\
Aortic valve disease & 42 \\
Mitral valve disease & I5 \\
Mixed aortic and mitral valve disease & 15 \\
Valve replacement & I0 \\
Cardiomyopathy & 19 \\
Others & 12 \\
\hline Total & 236 \\
\end{tabular}

The Judkins technique was used in the majority of patients. This technique (Judkins, 1967) involves introducing the catheter percutaneously into a femoral artery and advancing it over a guide wire to the aortic root. The catheter is preshaped, with a single end hole and, on withdrawing the guide wire, the coronary artery can readily be entered. Separate catheters have to be used for right and left coronary arteries, and their shape is different in that the left has two acute angles, which allows it to spring into the coronary artery while the right is straighter and usually requires a little more manipulation. The Amplatz catheters (Wilson et al., 1967) are also preshaped, have a single end hole, and are introduced percutaneously in a similar manner. They are looped from the opposite sinus of Valsalva into the coronary orifice.

The Sones technique (Sones and Shirey, 1962) is performed from a brachial arteriotomy. The catheters have a longer taper than either the Judkins or Amplatz catheters, with four side holes and an end hole. They are not preshaped and the same catheter is used for each coronary artery. This technique was used exclusively in the early part of this series and has again been used more frequently in recent months.

The category 'others' in the Tables includes the use of Amplatz catheters, Judkins catheters introduced from 
a brachial arteriotomy, and 16 patients in whom more than one technique was used because the operator had failed to enter the coronary artery with a Sones catheter. The patients in each group are comparable except that the Judkins technique was used for most of the emergency procedures, and avoided in patients with intermittent claudication. In every case, Conray $420(70 \%$ Sodium Iothalamate) was used as the opaque medium for left ventricular angiography and 76 per cent urografin (sodium and meglumine diatrizoate) for coronary arteriography.

\section{Mortality}

\section{Results}

There were 6 deaths, all of which occurred using Judkins technique (Table 2), giving an overall mortality rate of $I .5$ per cent. Four patients had coronary heart disease, one aortic valve disease, and one rheumatic mitral valve disease (Table 3 ). The mode of death varied. One patient with a left

TABLE 2 Mortality

\begin{tabular}{lrl}
\hline Technique & No. & Deaths \\
\hline Judkins & 248 & 6 \\
Sones & II I & 0 \\
Others & 4 I & 0 \\
\hline Total & 400 & 6 \\
\hline
\end{tabular}

TABLE 3 Details of deaths

\begin{tabular}{|c|c|c|c|}
\hline Age & Sex & Diagnosis & Mode \\
\hline 63 & $\mathbf{M}$ & $\begin{array}{l}\text { Coronary heart } \\
\text { disease }\end{array}$ & $\begin{array}{l}\text { Collapse - L. Judkins } \\
\text { in arch }\end{array}$ \\
\hline 46 & $\mathbf{M}$ & $\begin{array}{l}\text { Coronary heart } \\
\text { disease }\end{array}$ & $\begin{array}{l}\text { Collapse - L. Judkins } \\
\text { in arch }\end{array}$ \\
\hline 63 & $\mathbf{M}$ & $\begin{array}{l}\text { Mitral valve } \\
\text { disease }\end{array}$ & $\begin{array}{l}\text { Collapse - L. Judkins } \\
\text { in arch }\end{array}$ \\
\hline 64 & $\mathrm{M}$ & $\begin{array}{l}\text { Coronary heart } \\
\text { disease }\end{array}$ & $\begin{array}{l}\text { Collapse - L. Judkins } \\
\text { in arch }\end{array}$ \\
\hline 51 & M & Aortic valve & Pulmonary oedema \\
\hline $6 I$ & $\mathbf{M}$ & $\begin{array}{l}\text { Coronary heart } \\
\text { disease }\end{array}$ & $\begin{array}{l}\text { Atrial fibrillation - low } \\
\text { output }\end{array}$ \\
\hline
\end{tabular}

ventricular aneurysm went into atrial fibrillation during the procedure with progressive deterioration, despite cardioversion and operation. One sustained a myocardial infarct during the procedure and died in pulmonary oedema. The other 4 patients all died with the left Judkins catheter in the arch of the aorta. Haemodynamic measurements had been made in all, and left ventricular angiography performed in 3 ; but the left coronary artery had not been entered. In each case, the patient's deterioration was accompanied by hypotension and a bradycardia. The possible explanations for this phenomenon are discussed below.

\section{Morbidity}

The other complications of coronary arteriography are shown in Table 4. The four cases of myocardial

TABLE 4 Morbidity

\begin{tabular}{|c|c|c|c|c|}
\hline & \multicolumn{3}{|l|}{ Method } & \multirow[t]{2}{*}{ Total } \\
\hline & Judkins & Sones & Others & \\
\hline Myocardial infarction & 4 & 0 & 0 & 4 \\
\hline Prolonged bleeding & 7 & 0 & 0 & 7 \\
\hline Weak or absent pulse & 9 & 3 & 6 & $18(7 \cdot 2 \%)$ \\
\hline Dysrhythmia & IO & $\mathbf{I}$ & 2 & $13(5 \cdot 2 \%)$ \\
\hline accident & 2 & $\mathbf{I}$ & 0 & 3 \\
\hline Incomplete study & 13 & 8 & $\mathbf{I}$ & 22 \\
\hline Total & I 74 & 40 & 36 & 250 \\
\hline
\end{tabular}

infarction only occurred with the Judkins technique. Important arterial bleeding was also confined to this technique and probably reflected our practice of giving heparin when using the technique, but no patient required surgical exploration and all responded to digital pressure and/or protamine. Weak or absent pulses were relatively more common after brachial arteriotomy, as would be expected, since the Sones technique usually takes longer and involves more manipulation of the catheter, at least in our hands. Altogether 7 arteries (6 femoral, I brachial) had to be explored but only 2 patients were left with symptoms of limb ischaemia.

Transient minor dysrhythmias were frequent and only those who required treatment are included. These were more common with the Judkins than the Sones technique and consisted of ventricular fibrillation in 7 cases, asystole in 4 , and atrial fibrillation in 2. In only one case (Table 3 ) did the dysrhythmia recur after the end of the procedure, and this contributed to the patient's death. All 3 cerebrovascular episodes were short lived and the patient recovered completely. These were presumed to be embolic.

\section{Emergency investigations}

Eleven patients, all with coronary heart disease, were investigated as an emergency (Table 5). In I0 cases the Judkins technique was used, and in one, Amplatz catheters were used. There was one in- 


\section{TABLE 5 Indications for emergency investigation}

\begin{tabular}{lr} 
Recurrent ventricular tachycardia or fibrillation & 4 \\
Cardiogenic shock (including 2 with ruptured ventricu- & 3 \\
$\quad$ lar septum) & I \\
Mitral regurgitation & 2 \\
Left ventricular aneurysm & I \\
Unstable angina & II \\
\hline Total &
\end{tabular}

stance of ventricular fibrillation, one of ventricular tachycardia, and one patient subsequently required a femoral thrombectomy. No patient died as a result of the investigation and all proceeded to operation.

\section{Discussion}

The 1.5 per cent mortality rate from coronary arteriography is higher than that reported from other centres (Green et al., 1972; Ross and Gorlin, 1968; Bourassa et al., 1970). The commonest mode of death occurred in 4 patients who deteriorated while the left Judkins catheter was being manipulated in the arch or ascending portion of the aorta. Three of these patients had coronary heart disease while the other had mitral valve disease, atrial fibrillation, and recurrent cardiac pain at rest. At necropsy, this patient had normal coronary arteries but a circumferential subendocardial infarct whose distribution suggested that the infarction was secondary to hypotension, rather than vice versa. Necropsies were also performed on the other 3 patients and the diagnosis of severe coronary heart disease was confirmed in all. In no patient was there any evidence of arterial dissection. We feel that the most likely cause of the collapse in these patients was stimulation of the aortic baroreceptors, reflex vagal hypotension, and bradycardia. Cardiovascular collapse would be more likely to occur, and more difficult to reverse, in those patients whose myocardial blood supply was already jeopardized, and may be a special hazard of the angulated left Judkins catheter. None of the patients with coronary heart disease was taking beta-adrenergic blocking drugs at the time of their investigation. Three had received scopolamine with their premedication and intravenous atropine was used freely during resuscitation.

The only previous published report of this hazard of coronary arteriography is that of Lee and Amplatz (1968) who stated that more than 40 per cent of patients had vagal attacks. In their series subendocardial infarction occurred in 2 patients, with one death following such attacks, and they recommended the prompt administration of atropine. M. P. Judkins (1972, personal communication) is also aware of the potential risk of vagal reactions in patients undergoing coronary arteriography and he gives atropine with the premedication, together with further intravenous doses, and intra-arterial noradrenaline at the first sign of even mild hypotension. While the Amplatz and Judkins catheters are different, they are both angulated and might be more inclined to induce vagal reactions than the Sones catheter.

The other 2 deaths occurred in patients with severe coronary artery disease. One was due to cardiac infarction, and 4 other patients who survived also had clinical evidence of cardiac infarction sustained during the procedure. We believe this is more likely to occur with the Judkins catheters which have a short taper and a single end hole, as compared with the Sones catheters which have a longer taper and multiple side holes. It is thus possible to 'wedge' the Judkins catheter in the coronary ostium particularly if it is diseased, and render the myocardium ischaemic. This has occurred despite our policy of withdrawing the catheter if the pressure waveform recorded through the catheter is at all damped. There have been no deaths and no cases of cardiac infarction using the Sones technique.

The overall incidence of reduced or absent pulses after coronary arteriography is similar to that reported by others, e.g. 8.7 per cent (Gau et al., 1970), 5 per cent (Kasparian and Lehman, 1967); though higher than that of the largest series, e.g. I per cent (Green et al., 1972), and 0.5 per cent (Ross and Gorlin, 1968). This complication was more common with the Sones technique, particularly when other catheters were used in addition. Our increasing experience and ready use of Fogarty embolectomy catheters have led to this complication becoming less frequent in recent months.

In common with other centres (Gau et al., I970), we find the Sones technique more difficult and incomplete studies were more frequent as compared with the Judkins technique. The figure would have been even higher but for our policy of resorting to other techniques if we failed with the Sones catheter, either as a separate study or, in recent months, during the same study. We have found that the left Amplatz catheter can be readily introduced from the arm, though it was designed to be introduced percutaneously via the femoral artery, and can be used to enter both coronary arteries in most cases. In this respect, it is more useful than either Judkins catheter introduced from the arm.

The I I emergency investigations were not accompanied by any increased mortality or morbidity. All were performed with a view to operation with varying degrees of urgency. Three were in cardiogenic shock requiring vigorous supportive treatment and 
we were impressed by the lack of any further deterioration as a result of the investigation.

Our experience therefore suggests that the Judkins technique is more dangerous than the Sones technique and the risk of serious complications such as cardiac infarction and irreversible hypotension is greater. However, the Sones technique is more difficult, and local arterial complications and incomplete studies have been more frequent. This experience is very similar to that recently reported by Chahine, Herman, and Gorlin (1972) and we feel that the safety of the Judkins technique (Green et al., 1972) has been overestimated.

\section{Conclusion}

Our present policy is therefore to undertake coronary arteriography whenever it is indicated clinically, even though the patient may be very ill. The Sones technique is the safest in our hands and we prefer to use this but resort to Amplatz catheters when necessary, reserving the Judkins technique for emergencies where speed is essential.

\section{References}

Bourassa, M. G., Lespérance, J., Campeau, L., Bois, M. A., and Saltiel, J. (1970). Selective coronary angiography using a percutaneous femoral technique. Canadian Medical Association fournal, 102, 170.

Chahine, R. A., Herman, M. V., and Gorlin, R. (1972). Complications of coronary arteriography: comparison of the brachial to the femoral approach (abstract). Annals of Internal Medicine, 76, 862.
Favaloro, R. G. (1968). Saphenous vein autograft replacement of severe segmental coronary artery occlusion. Annals of Thoracic Surgery, 5, 334.

Gau, G. T., Oakley, C. M., Rahimtoola, S. H., Raphael, M. J., and Steiner, R. E. (1970). Selective coronary arteriography. A review of 18 months' experience. Clinical Radiology, 21, 275.

Green, G. S., McKinnon, C. M., Rösch, J., and Judkins, M. P. (1972). Complications of selective percutaneous transfemoral coronary arteriography and their prevention. Circulation, 45, 552.

Judkins, M. P. (1967). Selective coronary arteriography. A percutaneous transfemoral technic. Radiology, 89, 815 .

Kasparian, H., and Lehman, J. S. (1967). Coronary arteriography in myocardial ischaemia. Radiologic Clinics of North America, 5, 453.

Lee, G. B., and Amplatz, K. (1968). Selective coronary arteriography. fournal of the American Medical Association, 204, 444.

Ross, R. S., and Gorlin, R. (1968). Coronary arteriography. Circulation, 37, Suppl. 3, 67.

Ross, D., Sutton, R., Dow, J., Lavin, L. G., Hendrix, G., Jefferson, K., McDonald, L., Petch, M., Smithen, C., and Sowton, E. (1972). Venous graft surgery in treatment of coronary heart disease. British Medical fournal, 2, 644 .

Sones, F. M., and Shirey, E. K. (1962). Cine coronary arteriography. Modern Concepts of Cardiovascular Disease, 31, 735.

Wilson, W. J., Lee, G. B., and Amplatz, K. (1967). Biplane selective coronary arteriography via percutaneous transfemoral approach. American fournal of Roentgenology, 100, 332.

Requests for reprints to Dr. M. C. Petch, National Heart Hospital, Westmoreland Street, London WIM 8BA. 